\title{
A CULTURA E A FORMAÇÃO DE PROFESSORES ${ }^{1}$
}

\author{
CULTURA Y FORMACIÓN DOCENTE
}

\author{
CULTURE AND TEACHER TRAINING
}

\author{
Ariane Mieko Himeno ONOHARA ${ }^{2}$ \\ Ana Carla Fabian VASSELO ${ }^{3}$ \\ José Anderson SANTOS CRUZ ${ }^{4}$ \\ Maria Luiza MARIANO 5
}

RESUMO: Nessa resenha, enfatizaremos a importância da formação de professores, responsáveis pela alfabetização das crianças. Deste modo, destaca-se de que maneira ocorre a apropriação da escrita, utilizando e priorizando fatos e acontecimentos no cotidiano das crianças a partir das manifestações histórico-cultural. Corroborando nesse aspecto, o início da apropriação da linguagem escrita da criança. Diante desta perspectiva atentando ao analfabetismo funcional na didática aplicada.

PALAVRAS-CHAVE: Cultura. Desenvolvimento humano. Linguagem escrita. Formação de professores.

RESUMEN: En esta revisión, enfatizamos la importancia de la educación docente, responsable de la alfabetización de los niños. Así, es notable cómo se lleva a cabo la apropiación de la escritura, utilizando y priorizando hechos y acontecimientos en la vida cotidiana de los niños basados en manifestaciones histórico-culturales. Corroborando este aspecto, el comienzo de la apropiación de la lengua escrita del niño. En vista de esta perspectiva, considerando el analfabetismo funcional en la didáctica aplicada.

PALABRAS CLAVE: Cultura. Desarrollo humano. Lenguaje escrito. Formación de profesores.

\footnotetext{
${ }^{1}$ Está resenha foi elaborada a partir da leitura e discussão sobre o artigo em questão entre os autores. A qual diante dos questionamentos e indagações foi possível 'dialogar' com os autores do artigo em referência.

${ }^{2}$ Faculdade Anhanguera de Bauru, Bauru - SP - Brasil. Pedagoga. Agente Educacional- cuidador de jovens, crianças e adultos no município de Bauru. ORCID: <https://orcid.org/0000-0002-5602-6504>. E-mail: enairaono@yahoo.com.br

${ }^{3}$ Faculdade Anhanguera de Bauru, Bauru - SP - Brasil. Pedagoga. ORCID: <https://orcid.org/0000-0002-49440635>.E-mail: anacarla_vasselo@ hotmail.com

${ }^{4}$ Faculdade Anhanguera de Bauru, Bauru - SP - Brasil. Professor A do Departamento de Pedagogia Graduação. Doutorando em Educação Escolar pela Faculdade de Ciências e Letras (UNESP). ORCID: <https://orcid.org/0000-0001-5223-8078>.E-mail: joseandersonsantoscruz@ gmail.com

${ }^{5}$ Faculdade Anhanguera de Bauru, Bauru - SP - Brasil. Coordenadora e Professora do Departamento de Pedagogia e Psicologia - Graduação. ORCID: <https://orcid.org/0000-0002-9148-2732>. E-mail: maria.lalegria@anhanguera.com
} 
ABSTRACT: In this review, we emphasize the importance of teacher education, responsible for the literacy of children. Thus, it is noteworthy how the appropriation of writing takes place, using and prioritizing facts and events in the daily life of children based on historicalcultural manifestations. Corroborating this aspect, the beginning of the appropriation of the written language of the child. In view of this perspective, considering functional illiteracy in applied didactics.

KEYWORDS: Culture. Human development. Written language. Teacher training.

\section{Considerações iniciais}

A partir do momento em que a criança é inserida em um ambiente escolar, ela passa se desenvolver diante das atividades e percepções apropriadas para cada idade, e em no seu nível escolar. Inicia também, um trabalho relevante na vida dos alunos, com professores engajados na arte de ensinar. Desse modo as aulas são planejadas e executadas e seguem uma didática pautada na pedagogia histórico-crítica.

Esta resenha pauta-se no artigo publicizado na Revista Ibero-Americana de Estudos em Educação pela Universidade Estadual Paulista "Júlio de Mesquita Filho" (UNESP), na Faculdade de Ciências e Letras de Araraquara (FCL), no ano de 2016, tendo como discussão o trabalho dos professores alfabetizadores, de forma que o aluno se apropria da linguagem escrita como desenvolvimento humano.

O tema que é abordado no artigo, foi e continua sendo muito discutido no meio escolar, 'a formação de professores', objeto de estudo das autoras, Sônia Cláudia Barroso da Rocha, Doutora em Educação, e professora alfabetizadora da rede municipal de ensino de Manaus, juntamente com a Michelle de Freitas Bissoli, Doutora em Educação, e professora Associada da Universidade Federal do Amazonas.

\section{Apreciação crítica}

De acordo com as autoras, citam Marx e Engels (2002), os quais apontam que a apropriação da linguagem surge inevitavelmente a partir do meio da interação social ou seja na convivência entre as pessoas, assim despertando os estímulos. Dado a esse fato, considerase que qualquer pessoa seja capaz da percepção da linguagem, através das práticas culturais ocorridas nessa interação, sendo essencial para o desenvolvimento humano, desde o nascimento até a idade adulta, surgindo assim, diversas formas de expressão para se 
comunicar, destacando a habilidade da fala e de compreensão da fala, vista em toda sociedade.

Nesse contexto, Rocha e Bissoli (2016), relatam o ponto de vista de Vygotski (2012), que o dia a dia das pessoas tornam importantes, diante da cultura acumulada a qual, inseri nos objetos físicos e na linguagem, independente das classes sociais e com isso, obtém resultados na comunicação. Diante do que é relatado, não deve considerar a prática social de todas as crianças, existindo um abismo no gerar competência.

A partir das afirmações das autoras, apresenta a ideia de Smolka (2012), a qual revela que a apropriação da linguagem escrita surge como uma possibilidade de humanização da criança, no qual existe interação com a sociedade que aos poucos se tornam perceptíveis, os signos revelam significados e sentidos, surgindo assim o primeiro passo para adquirir a escrita, fundamentado em fatos transcorridos, que são expressados de forma representativa, que dessa maneira ocorre o desenvolvimento cognitivo e reflexivo.

Para se ter a apropriação da escrita na criança, é imprescindível a intervenção do adulto, fazendo o uso de vários tipos de grafismos, expressadas por meio de rabiscos, desenhos e letras reais ou inventadas, surgidas durante as trocas de atividades naturais e culturais, como por exemplo, nos 'jogos de papéis', favorecendo a compressão das trocas por meio das abstrações medidas.

$\mathrm{O}$ artigo relata ainda, que através da linguagem escrita a criança constrói o mundo e os signos, havendo novas apropriações mediante da assimilação do conhecimento já existente. Então em acordo, a educação escolar oferece estratégias de reflexão, de aprender e de participar da realidade concreta, como acontece quando é mostrado o objeto 'bola', questionando qual é a função social da 'bola', em que ocorre de maneira intencional da professora, objetivando o desenvolvimento do pensamento teórico do homem.

A partir disso, defendem que a apropriação da leitura e da escrita, a quem deve acontecer por intermédio da professora, relacionar a palavra 'bola' com a função social e auxiliando na mediação da palavra escrita dentro do contexto.

As autoras apresentam o ponto de vista de Mello (2000), o qual é possível encontrar professores que trabalham com palavras fragmentadas de sons e significados de uma tal maneira, em que não se adquire a apropriação da linguagem escrita, formando assim uma função mal interpretada da palavra.

Nesse artigo elaborado por Rocha e Bissoli (2016), em concordância, relatam que para haver o desenvolvimento integral, e os professores serem considerados geradores de conhecimento, devem preparar e planejar situações que favoreçam atingir a linguagem escrita, 
como trabalhar a vocalização - desenvolver habilidades a partir da tonação e a articulação bucal -, utilizar objetos para a oralidade e utilizar a linguagem como representação e expressão, objetivando a construção da alfabetização e proporcionando a apropriação da linguagem escrita.

Para tanto é importante que se considere sobre como professor consegue desenvolver em seus alunos determinadas capacidades. Ainda, é preciso que se pontue sobre como uma boa formação de professores de anos iniciais é necessária, mesmo que ainda hoje encontremos certas defasagens nesse processo de formação, em que, particularmente tem se consolidado um processo de disputas entre pontos de vista distintos.

Isso, porque muito se debate sobre o que significa, realmente, educar e quais as implicações necessárias a serem desenvolvidas para atuação nas escolas. De modo a tornar essas questões mais claras, as autoras relatam com vista de Martins que (2010, p. 14 apud ROCHA; BISSOLI, 2016, p. 981), afirma que, qualquer profissional, inclusive o professor, deve ter a sua formação entendida como "[...] uma trajetória de formação de indivíduos, intencionalmente planejada, para a efetivação de determinada prática social". Perante a está afirmação, percebe-se que faltam objetivos específicos à formação de professores de crianças e/ou educação infantil, no sentido de surgirem questionamentos como os que implicam sobre definir para que formar o professor, como e o que fundamenta o educar e qual conteúdo ensinar.

Diante a tantas perguntas, percebe-se que o esvaziamento na formação docente é recorrente nos últimos anos, em que esse é carente de teoria do mesmo modo que é da prática docente real e efetiva. Principalmente, quando se considera que são cursos e cargas horárias que se fundamentam sobre um curso muito teórico, que, na tentativa de solucionar o problema, busca, atualmente, a estimulação valorativa da prática em sua grade curricular.

Evidencia-se, portanto, uma tentativa de união entre teórica e prática, saber e ação na formação desses novos professores, de modo a fundamentar uma formação mais real e próxima da prática docente. Contudo, esta tentativa não solucionou a defasagem da formação, mantendo-a em muitos aspectos do processo de estudo, sendo mais uma tentativa de encontrar qual o caminho mais adequado a seguir nessa formação tão essencial em nossa sociedade.

Assim, nesse sentido valorativo sobre a prática docente, a tentativa de valorizar mais a profissão, não foi uma tentativa muito bem-sucedida quando levado em conta as mudanças na formação. Isso porque, não basta apenas memorizar um conjunto de ideias, que são trabalhadas em sala de aula, pois, sem ter o suporte teórico para se tornar um bom professor. Do mesmo modo, também não é suficiente a simples aplicação da técnica e prescrições 
descrita nos referenciais curriculares, sem que se tenha o conhecimento dos objetivos e possibilidades de intervenção na realidade vivenciada, sem fazer reflexões críticas da mesma.

Dito isso, concebe-se como não há como se discutir as teorias sem vivencia-las na prática, assim como não há meios de praticar sem ter o embasamento teórico. O que faz de ambas dependentes da formação do professor que atuará nas redes de ensino, e ainda, objeto de amplas discussões que buscam aperfeiçoamento, pois essas é que vão interferir sobre o professor atuante que mediará o conhecimento ao educando, formando um ser de pensamento mais elevado e crítico.

Logo, a apreensão da atual realidade vivenciada na formação docente, é fundamental para que se conceba a importância do trabalho a ser desenvolvido com as crianças. Pois a primeira implica e interage diretamente com a segunda, buscando formar um pensamento mais elevado e consciente, além de desenvolver nas crianças o processo de apropriação da linguagem escrita. Diante disso as autoras citam:

[...] Um curso de licenciatura para professores dos anos iniciais do ensino fundamental necessita promover o domínio dos saberes disciplinares a serem ensinados; a apropriação de metodologias, procedimentos e modos de ação, em função do trabalho na escola; e uma visão dos contextos em que se dá o ensino, para assegurar sua qualidade. (LIBÂNEO, 2013, p. 77 apud ROCHA; BISSOLI, 2016, p. 984).

Perante a afirmação de Libâneo (2013), percebemos que a carência da formação docente é bem maior do que apenas a falta de prática. Pelo contrário, evidencia uma má composição de currículos formativos, em que diante desse problema, consideramos que a formação é escassa diante as outras disciplinas que o professor precisa ter domínio para ensinar as crianças, como é caso das humanidades e biológicas, por exemplo. Como o professor precisa ter didática e domínio amplo de assuntos que são ensinados a seus alunos para poder mediar o conhecimento a eles, esses conteúdos fazem falta e formam uma ampla defasagem conceitual.

Dito isso, concebe-se como os métodos de ensino e conteúdos a serem aplicados dentro da abordagem do processo de apropriação da linguagem escrita precisam e devem ser sempre atualizados. As autoras Rocha e Bissoli de acordo com Chartier (1998, p. 4 apud ROCHA; BISSOLI, 2016, p. 985), nos chama a atenção para o caráter histórico-cultural dizendo "[...] o conteúdo e os métodos de ensino mudam à medida que a demanda social de alfabetização se transforma e, assim, as competências que se esperam dos professores não cessam de ser redefinidas". Diante da fala do autor, podem-se perceber que hoje vive-se em um constante processo de aprimoramento, em que devemos buscar aprender a aprender, 
sempre mantendo uma formação continuada do docente, buscando eliminar a visão retórica sobre o processo de alfabetização, e carregada de qualidade formacional. Seja na formação inicial ou continuada.

Assim, o professor precisa estar preparado para responder aos novos desafios que a educação o proporciona, sabendo sempre avaliar a qualidade do que e como ensina a seus alunos. Os estudos sobre a formação do professor que alfabetiza, ainda revelam que sua formação não conseguiu resolver o problema da relação teoria e prática, mostrando ser uma formação que ainda carece de muitos estudos para que seja resolvido o pertinente problema da teoria e prática.

\section{Considerações finais}

Pensar na formação de professores do ensino infantil é algo complexo, mas necessário. Pois, o obstáculo que vem acompanhando a formação do docente precisa ser sanado. Para isso é necessário que a formação possibilite ao professor que está sendo formado, situações em que ele próprio se aproprie do conteúdo a ser ensinado a suas crianças principalmente sobre os conteúdos da alfabetização, o próprio professor precisa se relacionar com a linguagem escrita como objeto cultural, vivenciando situações que aproximem os sentidos, atribuídos por ele ao ler e escrever, e o significado cultural da escrita.

A apropriação do conhecimento é o elemento chave, para a formação docente, é preciso que durante o processo de formação o professor tenha acesso a textos variados, e a uma cultura ampla, cabendo aos cursos de formação uma atenção especial à ampliação de referências a seus estudantes, para que eles tenham um maior número de fontes seguras para buscarem compreenderem as suas dúvidas. O professor de crianças precisa ser polivalente, pois precisa ensinar aos seus alunos conteúdos de diferentes mateiras além de devolver neles a linguagem escrita, para o mesmo tenha uma boa formação é preciso que as intuições que formam esse profissional reveja cada matéria da grade curricular, analisando se as mesma são capazes de formar profissionais capacitados para formar crianças, assim como é importante que em sua didática de ensino as faculdades relacione os conteúdos teóricos com práticas vivenciadas no contexto escolar, além de fomenta o gosto pela leitura nesses novos professores, para que eles também sejam incentivador na formação de novos leitores.

AGRADECIMENTOS: À CAPES - Coordenação de Aperfeiçoamento de Pessoal de Nível Superior. À Faculdade Anhanguera de Bauru. 


\section{REFERÊNCIAS}

ROCHA, Sônia Cláudia Barroso da.; BISSOLI, Michelle de Freitas. Desafios da formação de professores alfabetizadores: em busca da apropriação da linguagem escrita como desenvolvimento humano. Revista Ibero-Americana de Estudos em Educação, Araraquara, v. 11, n. esp. 4, p. 2499-2516, 2016. E-ISSN: 1982-5587. Disponível em: http://dx.doi.org/10.21723/riaee.v11.n.esp4.9206. Acesso em: 10 ago. 2018.

\section{Como referenciar}

ONOHARA, Ariane Mieko Himeno.; VASSELO, Ana Carla Fabian.; SANTOS CRUZ, José Anderson.; MARIANO, Maria Luiza. A cultura e a formação de professores. Temas em Educ. e Saúde, Araraquara, v. 14, n. 2, p. 295-301, jul./dez., 2018. e-ISSN 2526-3471. DOI: 10.26673/tes.v14i2.12033

Submetido em: 01/09/2018

Revisões requeridas: $23 / 10 / 2018$

Aprovado em: 18/11/2018 